\title{
A COMPARATIVE STUDY OF COLD KNIFE ADENOTONSILLECTOMY AND COBLATION ADENOTONSILLECTOMY
}

Col. S. K. Singh ${ }^{1}$, Sqn. Ldr. Anvita Bhansali ${ }^{2}$

\section{HOW TO CITE THIS ARTICLE:}

Col. S. K. Singh, Sqn. Ldr. Anvita Bhansali. "A Comparative Study of Cold Knife Adenotonsillectomy and Coblation Adenotonsillectomy". Journal of Evolution of Medical and Dental Sciences 2015; Vol. 4, Issue 51, June 25; Page: 8818-8826, DOI:10.14260/jemds/2015/1278

ABSTRACTS: AIMS \& OBJECTIVES: To compare intra and postoperative recovery after Cold dissection adenotonsillectomy (Procedure 1) and Coblation assisted adenotonsillectomy (Procedure 2) and to determine whether there is a significant difference between the two methods in terms of benefit to the patients. METHODS: A single blind comparative study of 60 pediatric patients aged 5 to 16 years undergoing adenotonsillectomy was conducted. The study assessed the results of two procedures in terms of duration, intra and post-operative bleeding, resumption to normal activity and quality of life assessment. The parameters were statistically compared between the two groups. RESULTS: 60 patients who underwent surgery (30 for cold dissection and 30 for coblation adenoton sillectomy) were found to have comparable demographic data with a mean age of 9.33 and 9.37 in procedure 1 \& 2 respectively. The distribution of symptoms and grades of adenoid and tonsil hypertrophy was found statistically insignificant. The duration of the surgical procedure was significantly higher in the coblation group with a mean of 29.18 minutes in comparison to the other procedure with a mean of 22.8 minutes. The blood loss was around $20 \mathrm{ml}$ for coblation versus $35 \mathrm{ml}$ for cold steel method which was significant. The mean pain scores at $6 \mathrm{hrs}$ post-surgery were low in coblation group, similar results were seen at $12 \mathrm{hrs}$ and again at 2 days there was low pain score. There was not much difference after 1 month in both the groups. Coblation procedure had a quicker return to normal diet with a mean duration of 2.67 days which was significant than the cold dissection method (mean-4.16 days). The quality of life scores were found similar in both the groups at the end of 6 months. CONCLUSION: The reduction of intraoperative blood loss in Coblation tonsillectomy was obvious and reduction of the postoperative pain and early return to normal diet were statistically significant. But the duration of surgery was found lengthened which can be attributed to inexperience. There was no significant variation recorded in long term pain and quality of life assessment.

KEYWORDS: Adenotonsillectomy, Coblation procedure, Cold steel procedure.

INTRODUCTION: The palatine tonsils form a part of Waldeyer's Ring which guard the oropharyngeal inlet. Its role in immunity is negligible as compared to its morbidity when they become the focus of recurrent infections. The earliest description of tonsillectomy appears in the medical encyclopedia of Cornelius Celsus in AD 30.[1] The operative procedures that emerged begin from the guillotine tonsillectomy to dissection and snare method, cryotonsillectomy, diathermy, harmonic scalpel, microdebrider, laser and coblator tonsillectomy. There have been lots of controversies about these techniques to provide more benefits and fewer complications and they are still trying to achieve ideality.

Cold dissection adenotonsillectomy is the conventional and gold standard with which the new techniques are compared.[2] It potentially minimizes morbidities associated with thermal injury. Coblation technology has recently surfaced as a potentially appealing technology for adenoton- 


\section{ORIGINAL ARTICLE}

sillectomy. Coblation is a contracted word for controlled ablation. Unlike traditional electrocautery methods, it employs radiofrequency ablation to remove tissues. ${ }^{[3]}$ It operates at much lower surface temperatures $\left(40-70^{\circ} \mathrm{C}\right)$ than electrocautery and provides both ablation and dissection of tissues and hemostasis with minimum thermal injury.

The idea of this study will be to compare the two methods and thus arrive at a conclusion. Even if it adds little to our knowledge the purpose of this study would be achieved.

MATERIALS \& METHODS: This study was approved by the ethical committee of our tertiary care centre. Pediatric population of the age group 5-16 with clinically documented history of chronic adenotonsillitis as per Paradise criteria and who failed medical treatment were enrolled. No bias of gender, socio economic status in sample selection is done. The group is not exposed to any increased risk as a result of the study. Patients with significant comorbidities such as systemic disease, known bleeding diathesis, craniofacial disorders, chromosomal abnormalities, or motor/developmental delays or those with peritonsillar abscess were excluded.

A verbal interview was conducted with the parent/guardian of the selected individuals. A written informed consent was obtained from the guardian of the patient before taking up for surgery and after explaining them that they are a part of the study. Only volunteers were enlisted. A questionnaire Pediatric Throat Disorders Outcome Tool ( $t-14)$ was given to the patients' relatives to assess the quality of life preoperatively and 06 months postoperatively. Pediatric Throat Disorders Outcome Tool (t-14) is a validated 14 item scoring questionnaire on a scale of 0 to 5 , thus creating a total score of 0 to 70 . The tool has two subscales, with the first 6 items as an obstructive domain and the remaining 8 as infective domain. This tool is used routinely used in United Kingdom as measure of health related Quality of Life of the child with tonsil and adenoid disease.

Patients, families and staff were blinded as to the technique. Every alternate patient was subjected to cold dissection method \& Coblation assisted method as per first come first serve basis. The procedure will be performed by a single surgeon only. Individual patient personal details would be kept confidential and will not be reported or published. The patients were admitted a day prior to the scheduled surgery. A thorough history, systemic \& ENT examination was done and recorded. Investigations including complete hemogram, bleeding parameters, routine urine examination \& microscopy estimation were carried out. Special investigations - HIV, HbsAg and Anti-HCV were also done.

The patients were sent for preoperative anesthetic checkup for general anesthesia with orotracheal/nasotracheal intubation. Operative room conditions were standardized for all patients. No antibiotics, topical or local anesthesia, or other medications were administered before surgery. All the procedures were performed by a single consultant surgeon who performed 20 surgeries prior to the study to reduce the learning curve bias.

Adenoidectomy was performed with a curette and cold-dissection tonsillectomy was performed using curved Blade no 12 to enter the peritonsillar space, blunt dissection to remove the tonsil from superior to inferior, and a wire snare to divide the inferior pole. Hemostasis was obtained with a bipolar cautery.

The Coblation-assisted Adenotonsillectomy was performed with the EVAC T \& A (Arthro Care ENT, Sunnyvale, CA) hand piece with Plasma 70 wand using subcapsular dissection along the tonsillar pillar mucosa, leaving muscle intact. Settings of the coblation device were standardized at seven (7) for coblation and three (3) for coagulation and adequate hemostasis was achieved. 
The operating nurse recorded the intraoperative time and blood loss based on the amount in the suction canister and the soaked gauze pieces at the end of each procedure. A standard size gauze measuring $10 \times 6 \mathrm{~cm}$ was taken ( $5 \mathrm{ml}$ for wet gauze and $10 \mathrm{ml}$ for dry one). Operation time was measured separately for adenoidectomy and tonsillectomy for both the procedures. Time for tonsillectomy was measured from incision on anterior pillar to the achievement of hemostasis was recorded. All patients were observed for a minimum of 2 hours following surgery in the postoperative room in the operation theatre.

All the children stayed in the hospital for at least 72 hrs after the surgery. Postoperative analgesic was only acetaminophen $(15-20 \mathrm{mg} / \mathrm{kg}$ per dose) in suppository, tablet or elixir form given 8 hourly. Oral antibiotics (Amoxicillin) were given five days post-surgery at $40 \mathrm{mg} / \mathrm{kg}$ daily in three divided doses. Postoperative care was the same in both groups. The postoperative pain was registered by the child, the parent and the nurse after 6hrs of surgery, then $12 \mathrm{hrs}, 24 \mathrm{hrs}$ and $48 \mathrm{hrs}$ after the surgery. A 10 point Visual Analog Scale was used and all the three observations were measured and a mean derived and recorded.

The parents recorded what kind and how much food the child ate after 6 hrs of surgery, then $12 \mathrm{hrs}, 24 \mathrm{hrs}$ and $48 \mathrm{hrs}$ after the surgery using a two - level scale"semisolid' (SS) or "normal (N). The patients were discharged on the $3^{\text {rd }}$ day and asked to review again on $6^{\text {th }}$ postoperative day when a history of the pain and return to normal diet was asked and recorded. A review was again done after 1 month, 3 and 6 months after surgery. Patients were examined for postoperative complications during post-surgical visits: primary hemorrhage, secondary hemorrhage and postoperative pain. The patients were advised to review for any complications if any, especially bleeding.

At 6 months the questionnaire Pediatric Throat Disorders Outcome Tool ( $\mathrm{t}-14)$ was given and assessment of quality of life for the past 6 months done and compared against the previous one filled prior to the surgery. Data were entered into an Excel sheet and analyzed using SPSS software (Statistical Package for Social Sciences, Windows, and version 19). All the variables were statistically analyzed and conclusions drawn accordingly.

DISCUSSION: Operations have been performed on the tonsil from the earliest times as long as 3000 years.[1]

The Coblation system is a plasmasurgical device for dissection of soft tissue using monopolar and bipolar coblation and hemostasis. ${ }^{[4,5]}$ The Coblation process was first invented by Philip Eggers and HV Thapliyal in May 1999. Their technology was acquired by a California based company Arthrocare and trademarked under the name COBLATION- a contraction of controlled and ablation. United States Food and Drug clearance was given in 2001.[6,7]

The first published study on the use of Coblation tonsillectomy was by Temple and Timms in 2001, which reported minimal postoperative pain with no episodes of postoperative hemorrhage in their study group of 38 children.[4] Subsequent studies have suggested that Coblation offers significant advantages in the post-operative period rapid return to normal diet and less postoperative pain than electrocautery.

Temple and Timms (2001) in another study compared Coblation with bipolar dissection for the removal of tonsils in 10 adult patients with a history of chronic adenotonsillitis. A significant decrease in post-operative pain and more rapid healing of the tonsillar fossae were found in the side removed by tissue Coblation.[3] Noon AP, Hargreaves S (2003) found a significant increase in the 
secondary hemorrhage rate in adult patients undergoing Coblation tonsillectomy (22.2 vs. 3.4 per cent) done in 36 patients versus cold dissection in 29 patients.[8]

In 2011, a meta-analysis of 796 patients who had undergone Coblation tonsillectomy in 24 prospective, randomized studies was done reported that hemorrhages occurred in 33 patients: 2 were primary and 26 secondary hemorrhages. Overall, the hemorrhage rate for Coblation procedure was found to be $4.1 \%(2.8 \%$ to $5.5 \%) .[5]$

The mean surgery time of Coblation tonsillectomy ranged from 22.7 to 28.9 minutes in various studies (Stoker et al, Parson et al, Shah et al)[9,10,11] compared to 16.2 to 23 minutes for electrocautery. In a study by R Guragain, CL Bhusal they concluded that the mean duration of dissection tonsillectomy was 23.03 minutes in comparison to diathermy tonsillectomy which was 14.8 minutes.[12] A study by Shah et al[11] (2002) the mean blood loss was estimated to be $90.9 \mathrm{ml}$ in Coblation tonsillectomy and $83.8 \mathrm{ml}$ in electrocautery group. While a study conducted by Parson et al in 2006 in 89 patients observed the bleeding in Coblation procedure to be only $21.5 \mathrm{ml}$ and $11.3 \mathrm{ml}$ in electrocautery tonsillectomy. Both of them found Coblation to be bloody than electrocautery procedure.

In a randomized study of 92 children Chang KW et al (2005) ${ }^{[13]}$ concluded that the Coblation group had a shorter operative time than the conventional group $(10.2 \mathrm{~min}$ vs. $36.5 \mathrm{~min}, \mathrm{P}<0.001)$. The average amount of intraoperative bleeding of Coblation assisted group was $(6.83+/-3.36) \mathrm{ml}$, while the control group was $(30.07+/-7.04) \mathrm{ml}$. Coblation group also had a better pain score on 1 st, $2^{\text {nd }}$ and $3^{\text {rd }}$ day after operation than in control group, and but there was no statistically significant difference on 4 to 10 days between the two groups. In our study, we encountered an median blood loss of $35 \mathrm{ml}$ in cold dissection tonsillectomy and $20 \mathrm{ml}$ in Coblation which demonstrated a significant variation among the two procedures ( $\mathrm{p}$ value $<0.001$ ).

Temple and Timms (2001) ${ }^{[4]}$ in their study reported a return to normal diet at a median of 2.4 days in comparison to the electrocautery group wherein the median was 7.6 days. While in a study by Stoker et al (2004) return to diet was longer in coblation group (Mean days-7.4) than in electrocautery group (mean - 6.7 days) which insignificant statistically. ${ }^{[9]}$ Mohammadreza Omrani, Behrouz Barati[14] in 2012 studied 47 patients in each group of Coblation and traditional tonsillectomy. Diet recovery period was found significantly shorter in the Coblation group (6.2 vs. 9.2 days $\mathrm{p}<0.001)$. Otherwise, return to normal general condition was significantly earlier in the Coblation group (7.6 vs. 11.0days $\mathrm{p}<0.001$ ).

Preoperatively the participating children and youths with obstructive problems and recurrent infections had a much lower Quality of Life with negative impact on their behaviour. In several studies upper airway obstruction and OSA have shown serious effects with disruption of school performance, and aggressive behaviour. A study by Susan L. Garetz, Ann Arbor[15] in 2008 assessed behaviour, cognition and quality of life in pediatric children with sleep disordered breathing after Adenotonsillectomy in 25 studies. Stewart et al reported[16]disease-specific Quality of Life with the Tonsil and Adenoid Health Status Instrument and global Quality of Life using the CHQPF -28 (Children's Health Questionnaire Parent Form) in 47 children with suspected Obstructive sleep disorders and showed that there was considerable improvement in behavior, polysomnography and quality of life post-surgery.

RESULTS: 60 children of the age group 5-16 were enrolled in the study groups over a period of 2 years out of which 30 underwent Cold dissection and 30 underwent Coblation adenotonsillectomy. 


\section{ORIGINAL ARTICLE}

The number of patients in each age group and gender were well distributed without much significance between the two groups. This resulted in an almost equal cohort of two groups with minimal internal bias. The mean age in procedure- I was found to be 9.33 years \pm 2.68 SD where as it was 9.37 years \pm 2.98 SD in procedure-II. The distribution of subjects in age groups was found to be similar with respect to both the procedure groups. Hence the influence of age on various factors was minimized. The majority of patients were from the age group 6-10 years (60\%). The study groups under observation in our study were both similar in distribution of age and gender, hence bias was minimized.

An incidence of symptoms related to Adenotonsillitis was noted in both the groups. Around 21 patients presented with mouth breathing/ snoring with an incidence of 35\% mostly seen in grade II/III adenoid hypertrophy. Difficulty in breathing was observed in only 4 patients $(6.66 \%)$ which was found only in grade III/IV tonsillar hypertrophy. One patient who had "kissing" Tonsils was the one who presented with most severe symptoms. Otalgia (referred), hearing complaints were present in only 3 patients(5\%), out of which 2 had Otitis Media with Effusion for which bilateral grommet were inserted and 1 had referred otalgia. Difficulty in swallowing was seen in $41.66 \%$ of patients.

\begin{tabular}{|c|c|c|c|c|c|}
\hline & \multirow{2}{*}{ Procedure } & \multicolumn{2}{|c|}{ Procedure done } & \multirow{2}{*}{ Total } & \multirow{2}{*}{ P-value } \\
\hline & & Procedure 1 & Procedure 2 & & \\
\hline \multirow{2}{*}{ Mouth Breathing/Snoring } & Yes & 12 & 9 & 21 & \multirow{2}{*}{0.589} \\
\hline & No & 18 & 21 & 39 & \\
\hline \multirow{2}{*}{ Difficulty in Breathing } & Yes & 3 & 1 & 4 & \multirow{2}{*}{0.612} \\
\hline & No & 27 & 29 & 56 & \\
\hline \multirow{2}{*}{ Ear Complaints } & Yes & 1 & 2 & 3 & \multirow{2}{*}{0.999} \\
\hline & No & 29 & 28 & 57 & \\
\hline \multirow{2}{*}{ Difficulty in swallowing } & Yes & 12 & 13 & 25 & \multirow{2}{*}{0.999} \\
\hline & No & 18 & 17 & 35 & \\
\hline
\end{tabular}

The mean duration of Tonsillectomy in procedure 1 was $22.8+/-4.13$ minutes and in procedure 2 was 29.18+/-6.85 minutes. The mean duration of adenoidectomy was 2.17 minutes in procedure 1 and 9.56 minutes in procedure 2. But the pooled mean difference of Tonsillectomy duration between the two groups was 13.77 minutes, hence significant ( $\mathrm{P}$ value $<0.001$ ). This can be attributed to the introduction of a relative new technique (Coblation) in our centre and the inexperience of the surgeon in handling the instrument. It was also observed that the initial few cases of Coblation Tonsillectomy took longer than the rest of the cases. In procedure 1 only one patient the duration exceeded 1900 seconds in which one tie was given in the left tonsillar fossa to control the intraoperative bleeding. 


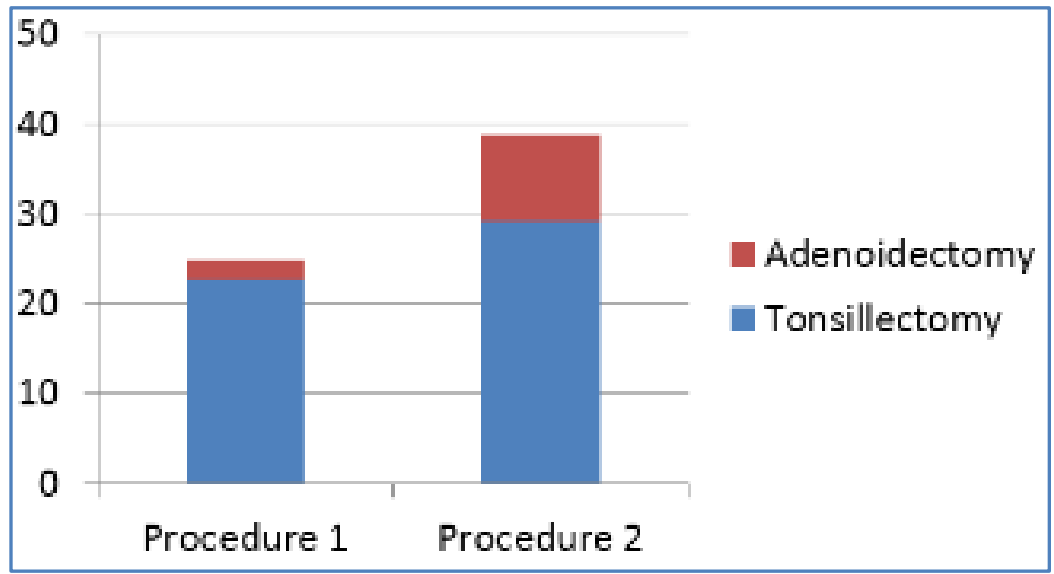

Graph 1: Duration of Adenotonsillectomy Procedure (In minutes)

In our study, we encountered an median blood loss of $35 \mathrm{ml}$ in cold dissection tonsillectomy and $20 \mathrm{ml}$ in Coblation which demonstrated a significant variation among the two procedures (p value $<0.001$ ). The difference in blood loss was found to be $15 \mathrm{ml}$ between the groups, which was significantly higher. The mean blood loss calculated for procedure 1 was $38.17+/-10.8 \mathrm{ml}$ while in procedure 2 was $20.5+/-5.1 \mathrm{ml}$. There was no statistically significant difference noted for the patients' age or sex and patients with any sort of bleeding disorders were already excluded.

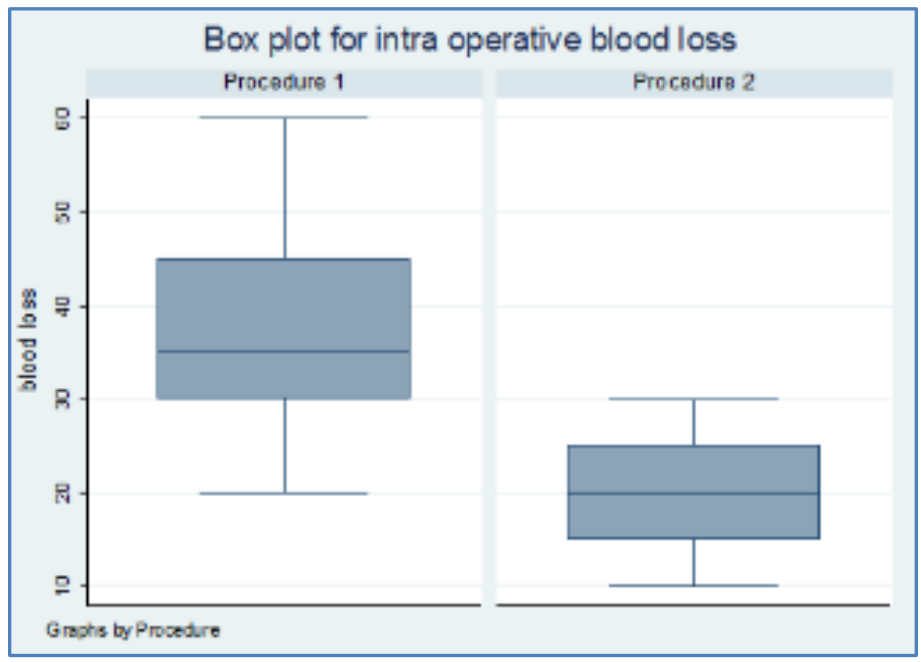

Graph 2: intraoperative blood loss (in $\mathrm{ml}$ )

The mean pain score at 6 hours was 6.4 for the dissection group and 5.8 for the Coblation group ( $p$ value $<0.001$ ), hence found significant. The median was 8 in both the procedure groups. The mean pain score at 12 hours was not found significant between the two procedure groups. But again after day 2 there was significant lowering of pain scores observed in the Coblation group (mean - 2.1) compared to dissection group (mean 4.1). Scores at 1 month, 3 month and 6 months were similar in both the procedure groups. Thus Coblation Tonsillectomy was found similar to dissection method in long term pain outcomes. 


\section{ORIGINAL ARTICLE}

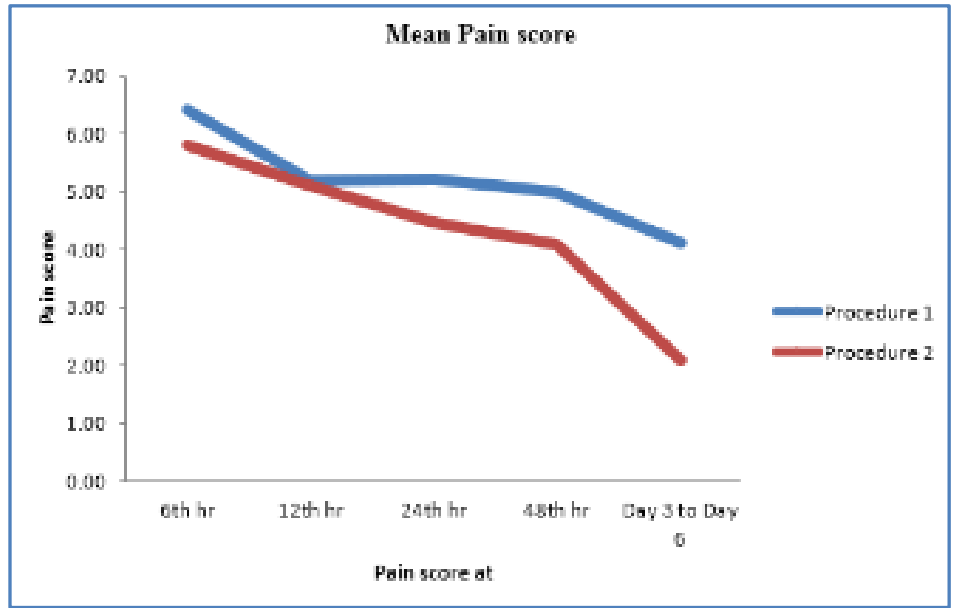

Graph 3: Trend of fall of postoperative pain

At 12 hours postoperatively in our study, all patients had semisolid diet irrespective of the procedure performed. At 24 hours 10\% patients in procedure1 consumed normal diet while $40 \%$ returned to normal diet in procedure 2 which was statistically significant. $43.3 \%$ in procedure 1 and $73.3 \%$ in $2^{\text {nd }}$ group returned to normal diet. All patients when they reported at $6^{\text {th }}$ postoperative day in OPD for review had normal diet. Coblation assisted procedure had a quicker return to normal diet with a mean duration of 2.67 days which was significant than the cold dissection method (mean- 4.16 days). But at the end of 6 days there was no significant variation observed in the two procedure groups.

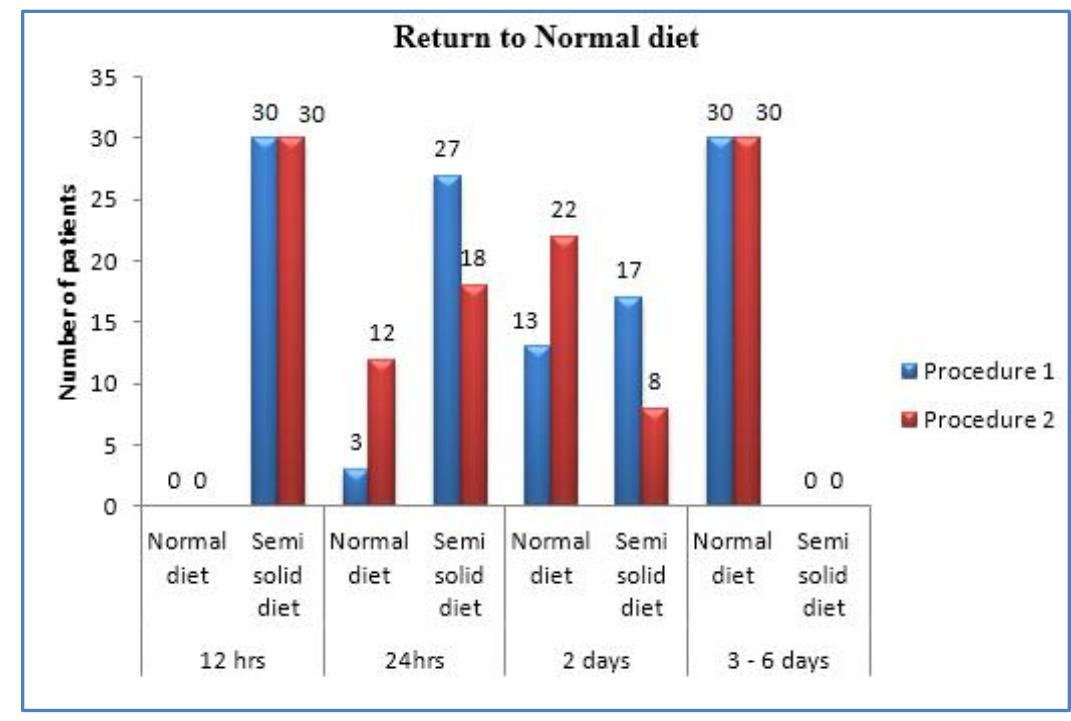

\section{Graph 4: Return to normal diet}

There were no incidences of any post tonsillectomy hemorrhages noted in any of the groups. In our study we assessed the quality of life using a validated Paediatric Throat Disorders Outcome Tool. The mean score preoperatively assessing the patients' quality of life for the last 6 months was similar in both the groups (Dissection - 14.97 +/- 5.57 and Coblation- $16.27+/-6.53$ ). 


\section{ORIGINAL ARTICLE}

The scores showed an improvement to $2.33(84.4 \%)$ in procedure 1 and to $2.5(84.6 \%)$ in procedure 2. Thus the observation was not found significant at 6 months post-surgery in any of the group.

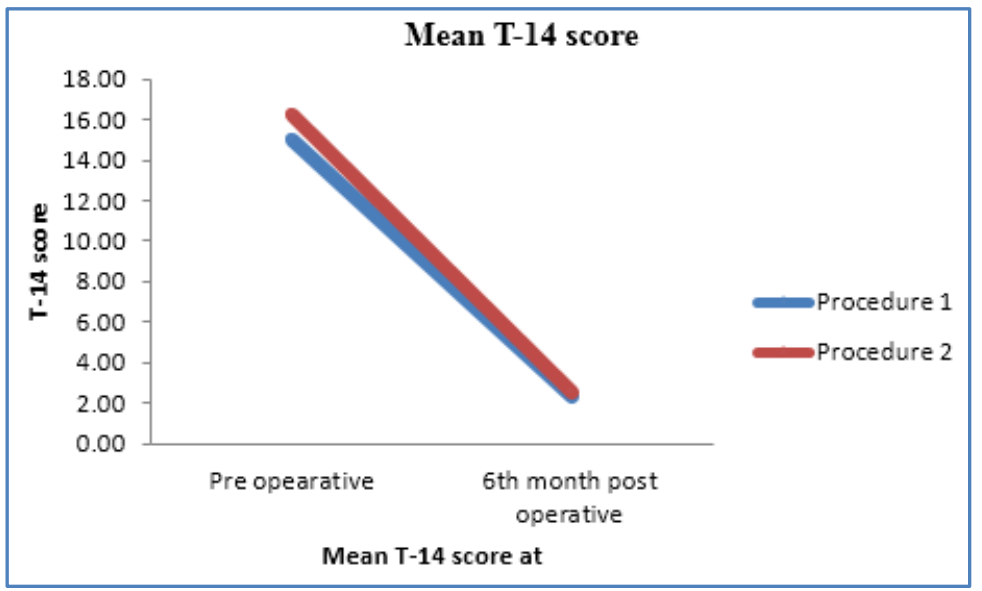

Graph 5:Pediatric throat disorders outcome tool (T-14 score)

CONCLUSION: Adenotonsillectomy is a common surgery in Otolaryngology practice. There is no consensus on the optimum method of doing it. Many studies in literature have been described and compared but still the search continues.

Coblation tonsillectomy is a relatively safe method of tonsillectomy in pediatric population. Coblation tonsillectomy was seen to significantly reduce intraoperative blood loss and postoperative pain, and was associated with early recovery of dietary routine. But the long term benefits are similar to the dissection method. Also it was found as safe and reliable as the traditional diathermy tonsillectomy as there were no postoperative hemorrhages encountered. More and more experience in this surgical technique will reduce the intraoperative time as well. In pediatric age group reducing the intraoperative blood loss is of utmost importance as the circulating blood volumes is already less and increased losses may delay the recovery time. These two factors are appealing to the surgeon and are of importance considering the pediatric population. We recommend this instrument as a suitable alternative method of tonsillectomy.

\section{REFERENCES:}

1. Glover, E. E. V. (1918).Historical account of Tonsillectomy. Brit. med. J., 2, 685-687.

2. Pinder DK, Wilson H, Hilton MP. Dissection versus diathermy for tonsillectomy. Cochrane Database Syst Rev.2011;(3):CD002211.

3. Timms MS, Temple RH. Coblation tonsillectomy: a double blind randomized controlled study.J Laryngol Otol.2002;116(6):450-2.

4. Temple RH, Timms MS. Paediatric coblation tonsillectomy. Int J Pediatr Otorhinolaryngol 2001; 61: 195-198.

5. Mosges R, Hellmich M, Allekotte S, Albrecht K, Bohm M. Hemorrhage rate after coblation tonsillectomy: a meta-analysis of published trials. Eur Arch Otorhinolaryngol 2011;268:807816. 


\section{ORIGINAL ARTICLE}

6. SV. Belov Use of high frequency cold plasma ablation technology for electrosurgery with minimum invasiveness. Biomedical Engineering. Vol. 38 no. 2 2004. Pp 80-5.

7. Vikash K Modi, MD Histologic assessment of thermal injury to tonsillectomy specimens: A comparison of electrocautery, coblation, harmonic scalpel and tonsillotome. Laryngoscope 119:Nov 2009, 2248.

8. Noon AP, Hargreaves S. Increased post-operative haemorrhage seen in adult coblation tonsillectomy. J Laryngol Otol. 2003 Sep;117(9):704-6.

9. Stoker KE, Don DM, Kang DR, Haupert MS Pediatric total tonsillectomy using coblation compared to conventional electro surgery: a prospective, controlled single-blind study. Otolaryngol Head Neck Surg.2004 Jun;130(6):666-75.

10. Parsons SP, Cordes SR, Comer B. Comparison of postton sillectomy pain using the ultrasonic scalpel, coblator, and electrocautery. Otolaryngol Head Neck Surg. 2006 Jan; 134 (1):106-13.

11. Susan L. Garetz, MD, Ann Arbor, MI; Behavior, cognition, and quality of life after adenoton sillectomy for pediatric sleep-disordered breathing: Summary of the literature. Otolaryngology-Head and Neck Surgery (2008) 138, S19-S26.

12. Shah, U. K., Galinkin, J., Chiavacci, R., and Briggs, M. (2002). Tonsillectomy by means of plasmamediated ablation - Prospective, randomized, blinded comparison with monopolarelectro surgery. Archives of Otolaryngology-Head \& Neck Surgery 128, 672-676.

13. Chang KW; Randomized controlled trial of Coblationversus electrocauteryton sillectomy. Otolaryngol Head Neck Surg. 2005 Feb; 132 (2): 273-80.

14. Izny Hafiz Z, Rosdan S, Coblation tonsillectomy versus dissection tonsillectomy: a comparison of intraoperative time, intraoperative blood loss and post-operative pain.Med J Malaysia.2014 Apr; 69 (2):74-8.

15. Wei JL, Beatty CW, Gustafson RO. Evaluation of post tonsillectomy hemorrhage and risk factors. Otolaryngol Head Neck Surg2000; 123:229-235.

16. Mohammadreza Omrani, Behrouz Barati; Coblation versus traditional tonsillectomy: A double blind randomized controlled trial. J Res Med Sci. Jan 2012; 17(1): 45-50.

\section{AUTHORS:}

1. Col. S. K. Singh

2. Sqn. Ldr. Anvita Bhansali

\section{PARTICULARS OF CONTRIBUTORS:}

1. Associate Professor, Department of ENT, Armed Forces Medical College, Pune.

2. Resident, Department of ENT, Armed Forces Medical College, Pune.

FINANCIAL OR OTHER COMPETING INTERESTS: None
NAME ADDRESS EMAIL ID OF THE CORRESPONDING AUTHOR:

Dr. Sqn. Ldr. Anvita Bhansali, Department of ENT,

Armed Forces Medical College, Pune.

E-mail: smart_doc_anvita@yahoo.co.in

Date of Submission: 20/05/2015.

Date of Peer Review: 23/05/2015.

Date of Acceptance: 18/06/2015.

Date of Publishing: 23/06/2015. 